\title{
BMJ Open Effectiveness of community health worker training programmes for cardiovascular disease management in low-income and middle-income countries: a systematic review
}

\author{
Marwa Abdel-All, ${ }^{1,2}$ Barbara Putica, ${ }^{2}$ Deversetty Praveen, ${ }^{3}$ Seye Abimbola, ${ }^{1,2}$ \\ Rohina Joshi ${ }^{1,2,4}$
}

To cite: Abdel-All M, Putica B, Praveen D, et al. Effectiveness of community health worker training programmes for cardiovascular disease management in low-income and middle-income countries: a systematic review. BMJ Open 2017;7:e015529. doi:10.1136/ bmjopen-2016-015529

- Prepublication history and additional material for this paper are available online. To view these files, please visit the journal online (http://dx.doi org/10.1136/bmjopen-2016015529).

Received 11 December 2016 Revised 13 September 2017 Accepted 15 September 2017

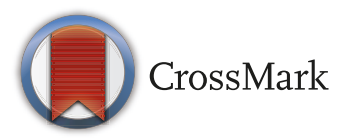

${ }^{1}$ The George Institute for Global Health, Sydney, New South Wales, Australia

${ }^{2}$ Sydney Medical School, University of Sydney, Sydney, New South Wales, Australia

${ }^{3}$ The George Institute for Global Health, Hyderabad, Telangana, India

${ }^{4}$ Faculty of Medicine, University of New South Wales, Sydney, New South Wales, Australia

Correspondence to Marwa Abdel-All; mabdel-all@georgeinstitute. org.au

\section{ABSTRACT}

Introduction Community health workers (CHWs) are increasingly being tasked to prevent and manage cardiovascular disease (CVD) and its risk factors in underserved populations in low-income and middleincome countries (LMICs); however, little is known about the required training necessary for them to accomplish their role. This review aimed to evaluate the training of CHWs for the prevention and management of CVD and its risk factors in LMICs.

Methods A search strategy was developed in line with Preferred Reporting Items for Systematic Reviews and Meta-Analyses guidelines, and five electronic databases (Medline, Global Health, ERIC, EMBASE and CINAHL) were searched to identify peer-reviewed studies published until December 2016 on the training of CHWs for prevention or control of CVD and its risk factors in LMICs. Study characteristics were extracted using a Microsoft Excel spreadsheet and quality assessed using Effective Public Health Practice Project's Quality Assessment Tool. The search, data extraction and quality assessment were performed independently by two researchers.

Results The search generated 928 articles of which 8 were included in the review. One study was a randomised controlled trial, while the remaining were before-after intervention studies. The training methods included classroom lectures, interactive lessons, e-learning and online support and group discussions or a mix of two or more. All the studies showed improved knowledge level post-training, and two studies demonstrated knowledge retention 6 months after the intervention.

Conclusion The results of the eight included studies suggest that CHWs can be trained effectively for CVD prevention and management. However, the effectiveness of CHW trainings would likely vary depending on context given the differences between studies (eg, CHW demographics, settings and training programmes) and the weak quality of six of the eight studies. Wellconducted mixed-methods studies are needed to provide reliable evidence about the effectiveness and costeffectiveness of training programmes for CHWs.
Strengths and limitations of this study

- First systematic review to evaluate the effectiveness of training community health workers for the prevention and management of cardiovascular disease and its risk factors in low-income and middle-income countries.

- The review was conducted in accordance to the Preferred Reporting Items for Systematic Reviews and Meta-Analyses guidelines.

- Quality of studies was assessed and papers were critically appraised using Effective Public Health Practice Project's Quality Assessment Tool.

- Limited number of studies with insufficient data regarding training methods, outcomes and characteristics of CHWs.

- Most of the studies were not controlled, which made it difficult to investigate the effect of potential confounders on the performance of the CHWs.

\section{INTRODUCTION}

Cardiovascular diseases in low-income and middle-income countries

Globally, the burden of non-communicable diseases (NCDs) is rising with the cause-specific mortality fraction due to NCDs estimated to be $69 \%$ in 2030 compared with $59 \%$ in 2002. ${ }^{1}$ This shift is largely driven by a demographical and epidemiological transition, coupled with rapid urbanisation and nutritional transitions in low-income and middle-income countries (LMICs). ${ }^{2}$ Currently, cardiovascular disease (CVD) is the leading cause of morbidity and mortality in developed countries and LMICs alike, with a greater burden being felt by the latter, as they carry a higher proportion of premature deaths from cardiovascular events. ${ }^{3}$ Most health systems in LMICs are unprepared to manage the increasing burden of CVDs 
as their health systems are often focused on infectious diseases and maternal and child health, rather than chronic diseases. ${ }^{56}$

\section{Health workforce for CVD}

Access to primary care for CVD prevention and treatment in LMICs can often be challenging ${ }^{7}$ as these countries have the highest global disease burden and tend to experience some of the greatest shortages in physicians and health workers. ${ }^{8}$ For example, there are 2.3 health workers per 1000 population in Africa and 4.3 per 1000 population in Southeast Asia. ${ }^{9}$ A maldistribution of these health workers often exists with a higher concentration of health workers in urban areas compared with rural regions where large proportions of the population reside..$^{9-11}$ This poor distribution and shortage of health professionals has led some countries to rely on trained community health workers (CHWs), who take on specific tasks for the prevention and management of diseases.

\section{Community health workers}

WHO defines CHWs as individuals who perform functions related to healthcare delivery, have shorter training than professional health workers, are community members, selected by and answerable to the community for their activities and are usually supported by the health system but not necessarily a part of its organisation. Typically, they are trained for specific tasks such as provision of antenatal care or immunisation and often do not hold any formal certifications. ${ }^{12}$ CHWs have been effective in providing essential healthcare services in a cost-effective manner. ${ }^{1314}$ They have been instrumental in reducing maternal and neonatal mortality rates through their presence in at-home births and making referrals for emergency obstetric care ${ }^{15-17}$ and by promoting vaccination uptake, breast feeding and education on infectious disease. ${ }^{18}{ }^{19}$ More recently, CHWs have been useful in HIV/AIDS prevention and control, educating communities and performing tasks such as testing, counselling and prescribing antiretroviral drugs. ${ }^{20-24}$ This transfer of responsibilities onto CHWs is commonly referred to as task shifting, which is common in regions with limited access to physicians. ${ }^{25-27}$ This increase in responsibility has been noted throughout the global health community, and it is not uncommon for CHWs to hold different titles based on the country where they work or the tasks for which they are responsible (such as non-physician healthcare worker, lay health worker, traditional birth attendant, accredited social health activist, barangay health worker, etc) ${ }^{12}$

Over the last 10 years, CHWs have had an increasing role in CVD prevention and control. ${ }^{28-32}$ Although research into the effect of CHWs in CVD prevention and control is relatively new, there is emerging evidence that yields promising results. ${ }^{33-36}$ There is considerable amount of data and manuals available to help train CHWs for management of infectious diseases and maternal and child health in LMICs ${ }^{37-39}$; however, there is a lack of evidence-based information regarding the content and method to train CHWs for CVD prevention and control. ${ }^{40}$ Effective training and retraining are essential for the knowledge and skill set required for good quality performance. This systematic review aims to provide comprehensive insight into CHW training programmes for CVD prevention and control and provides an evidence base for the effectiveness of training programmes in the LMIC context.

\section{METHODS}

A protocol was written to define the inclusion and exclusion criteria and the methods for the review prior to data extraction in accordance to the Preferred Reporting Items for Systematic Reviews and Meta-Analyses guidelines. ${ }^{41}$ Five databases including Medline via OvidSP, Global Health via OvidSP, ERIC via OvidSP, Embase via OvidSP and CINAHL via EBSCO were reviewed.

\section{Inclusion and exclusion criteria}

The population considered for this systematic review was CHWs in LMICs. Synonyms for CHWs included in the search were taken from the WHO report on $\mathrm{CHWs}^{12}$ and other terms based on literature reviews. ${ }^{42-44} \mathrm{~A}$ medical librarian was consulted to ensure integrity of our search. The review included intervention studies that offered training programmes for CHWs in CVD and cardiovascular risk factor prevention (screening, health promotion) or control (monitoring, management). Papers included were specific in what type of training methods were used (ie, which topics were covered, length and outcomes of the training programmes, etc). Studies were limited to CVDs and their modifiable risk factors including high blood pressure, diabetes, dyslipidaemia, alcohol consumption, tobacco use and physical inactivity. A complete list of free text search terms and subject headings are supplied in online supplementary appendix 1. The comparator variable for this paper included preservice training, and the outcome of interest was an improvement in skills and knowledge of CHWs in the prevention and control of CVDs and their risk factors after the training programme. Types of studies included were preobservational and postobservational studies and randomised controlled trials published until 31 December 2016. Papers in all languages were searched, and those in a language other than English were translated. If a study was reported in more than one paper, information from all the papers was included in the review, but the study was counted once.

Studies were limited to those that were explicit in specifying what type of training was done and reported pretest and post-test scores for CHWs. They included countries classified during 2015 as low-income, lower-middle-income and upper-middle-income countries in the World Bank's Income Classifications. ${ }^{45}$

\section{Data collection}

After agreeing on the search strategy to be used, two authors (BP, MA) reviewed the literature and extracted 


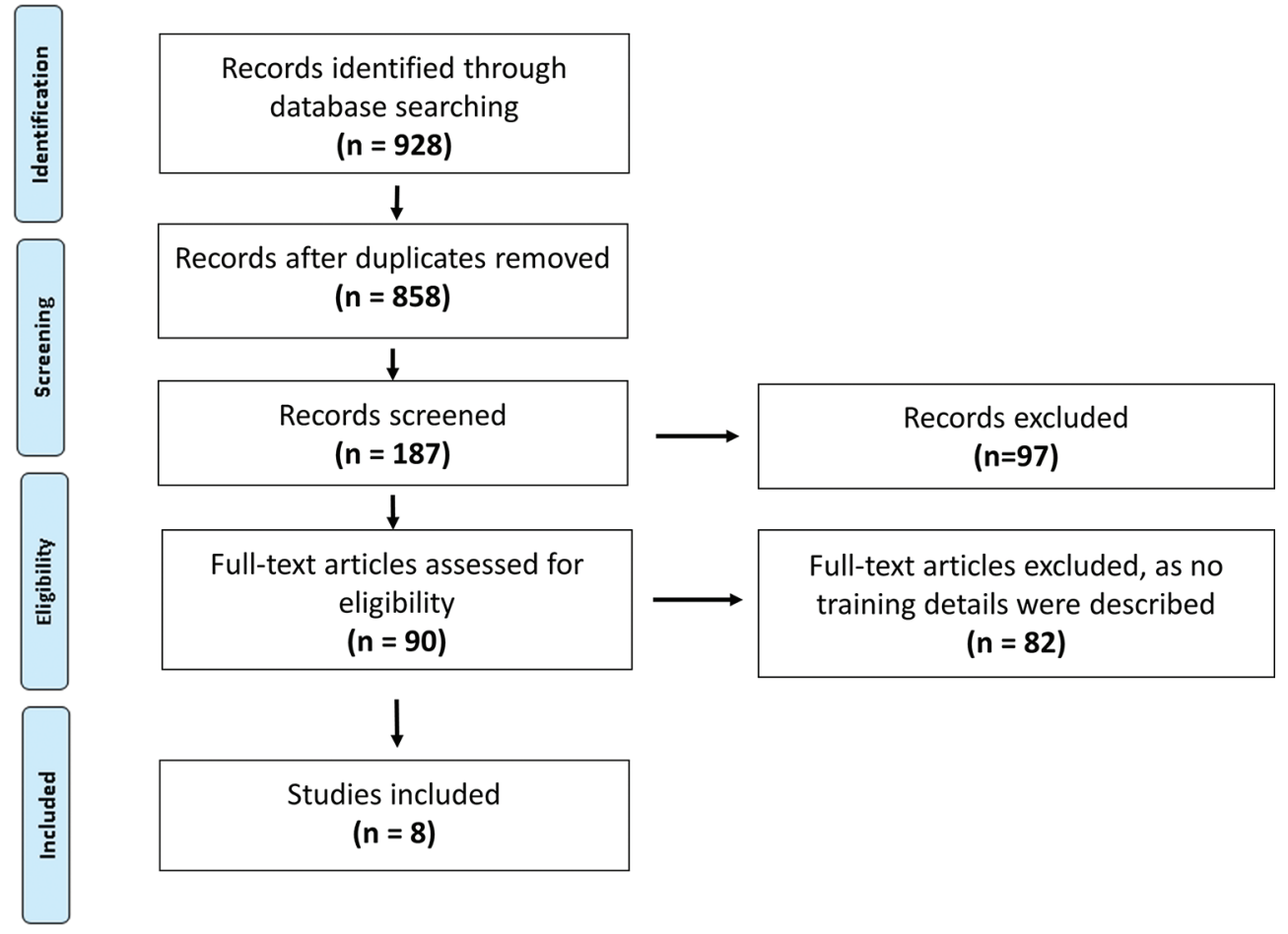

Figure 1 Flow diagram for systematic review process.

the data independently. The number of studies included at each stage of literature search was agreed on between the two authors to ensure that no papers were missed and discrepancies were dealt by consensus (figure 1). Data were collected on a prespecified Excel sheet after approval of all reviewers, with variables clearly outlined. The first paper to be included was extracted independently and then the data were compared between authors to confirm what was to be expected to report for each variable. This sheet was modified to include all information that was important as data extraction continued. Weekly meetings were held between the data extractors to discuss any disagreements about the inclusion of a paper. In case of disagreements, a third author (RJ) was asked to adjudicate. At the end of data extraction, all reviewers met to note any discrepancies and agree on the final data extraction. The references of all the included papers were checked for additional relevant papers. When necessary, corresponding authors of included papers were contacted regarding missing information in the published papers. Quality of studies was assessed and papers were critically appraised using Effective Public Health Practice Project (EPHPP)'s Quality Assessment Tool. ${ }^{46}$ The Tool provides an overall methodological rating of the studies of strong, moderate or weak as per six components including selection bias, study design, confounders, blinding, data collection methods, withdrawals and dropouts. Studies were rated strong if the study population was representative of the target population, had a robust study design such as a randomised controlled trial, controlled for confounding, used validated data collection tools and had a low drop-out rate of the study participants. Two authors (BP, MA) followed the quality assessment tool and rated the studies independently and discussed discrepancies by consensus. No study was excluded based on the quality assessment.

\section{Data analysis}

To demonstrate the change in knowledge and skills among CHWs, pretest and post-test scores and postintervention scores published in the eight papers were used to evaluate the effectiveness of training. No additional statistical analysis was done as individual test scores were not available and scores were not standardised across the eight studies. All studies were reviewed and a narrative synthesis was conducted to assess the studies comprehensively. The data were tabulated to explore the relationship between and within the included studies. Themes from the qualitative data reported were used to assess the CHWs' perception and experience of the training. A meta-analysis was not performed due to heterogeneity of the studies.

\section{RESULTS}

\section{Characteristics of included studies, CHWs and trainers}

The initial search yielded 928 citations published between the period of 1959 and 2016. After removing duplicates, 858 titles and 187 abstracts were screened. Ninety studies were assessed for a full review, of which 8 studies were included. Figure 1 outlines the systematic review process. The selected studies were conducted between the year 2000 and 2013 and published between the year 2007 and 2015. Four of the studies were conducted in rural or semiurban areas, and four studies did not mention details about the study site. ${ }^{47-50}$ None of the studies discussed the cost of training involved or the cost-effectiveness of the training. 
The studies included CHWs from Bangladesh, Guatemala, Mexico, South Africa ${ }^{51}$ and Thailand ${ }^{52}$; community health agents from Brazil ${ }^{48}$; cadres posbindu and community health centre staff from Indonesia ${ }^{49}$; barangay health workers from the Philippines ${ }^{53}$; female health workers from Pakistan ${ }^{54}$; and healthcare volunteers from $\operatorname{Iran}^{50}$ and Thailand. ${ }^{47}$ The number of trained health workers varied from $35^{52}$ to $299^{54}$ and were mostly women $(75 \%-$ $100 \%)$. The education of CHWs varied from primary school $^{4753}$ to master degree holders. ${ }^{51}{ }^{52}$ In most studies, the health workers were part of the health system receiving a salary, except in Guatemala where a monthly incentive was provided, ${ }^{51}$ and Iran and Thailand, where CHWs were volunteers from the community. ${ }^{47} 50$ The training team included health professionals, ${ }^{51}$ project officers ${ }^{54}$ and researchers. ${ }^{48}$ Four studies did not provide details about the trainers. ${ }^{47495052}$ Detailed characteristics of the CHWs and trainers are provided in table 1.

\section{Details regarding training methods}

Studies used different approaches to develop the curriculum and disseminate knowledge. Training methods included interactive modes like problem-based learning, classroom discussions, demonstrations, media presentations, role plays, as well as self-training quizzes and assignments, which were either online ${ }^{52}$ or paper based. ${ }^{51}$ Training designs included the T5 instructional learning design (tasks, tutorials, tools, topics and teamwork), allowing interactive learning, ${ }^{55}$ or adapting existing education and training materials available from high-income countries. ${ }^{51}$ In one of the studies, CHWs were trained alongside nurses on hypertension, its treatment and its

Table 1 Characteristics of community health workers and trainers

\begin{tabular}{|c|c|c|c|c|c|c|c|}
\hline Study & $\begin{array}{l}\text { Type of health } \\
\text { workers } \\
\text { (country of } \\
\text { study) }\end{array}$ & $\begin{array}{l}\text { CHWs } \\
\text { (n) }\end{array}$ & Sex & Age & Education & $\begin{array}{l}\text { Relation to } \\
\text { health system }\end{array}$ & Trainers \\
\hline Da Silva et $a{ }^{48}$ & $\begin{array}{l}\text { Community } \\
\text { health agents } \\
\text { (Brazil) }\end{array}$ & 37 & $\begin{array}{l}90.9 \% \\
\text { females }\end{array}$ & $\begin{array}{l}50 \% \text { of } \mathrm{CHWs} \\
\text { were up to } \\
40 \text { years }\end{array}$ & $\begin{array}{l}\text { Secondary } \\
(67.3 \%)\end{array}$ & $\begin{array}{l}\text { Government } \\
\text { employed }\end{array}$ & Researchers \\
\hline $\mathrm{Ku}$ and Kegels ${ }^{53}$ & $\begin{array}{l}\text { Barangay } \\
\text { health worker } \\
\text { (Philippines) }\end{array}$ & 87 & $\begin{array}{l}\text { Not } \\
\text { reported }\end{array}$ & Not reported & $\begin{array}{l}\text { Primary }(8 \%) \text {, } \\
\text { secondary }(42 \%) \text {, } \\
\text { university }(50 \%)\end{array}$ & $\begin{array}{l}\text { Government } \\
\text { employed }\end{array}$ & $\begin{array}{l}\text { Principal } \\
\text { investigators } \\
\text { and trained } \\
\text { nurses }\end{array}$ \\
\hline Nishtar et $a l^{54}$ & $\begin{array}{l}\text { Female health } \\
\text { worker (Pakistan) }\end{array}$ & 299 & $\begin{array}{l}100 \% \\
\text { females }\end{array}$ & Not reported & Not reported & $\begin{array}{l}\text { Government } \\
\text { employed }\end{array}$ & $\begin{array}{l}\text { Heartfile Officer } \\
\text { (project officer) }\end{array}$ \\
\hline Sangprasert ${ }^{47}$ & $\begin{array}{l}\text { Healthcare } \\
\text { volunteer } \\
\text { (Thailand) }\end{array}$ & 75 & $\begin{array}{l}75 \% \\
\text { females }\end{array}$ & Mean age 49.5 & $\begin{array}{l}\text { Primary }(56.4 \%) \text {, } \\
\text { secondary } \\
(30.1 \%) \text {, diploma } \\
(9.7 \%) \text {, } \\
\text { university }(3.8 \%)\end{array}$ & Volunteers & Not reported \\
\hline
\end{tabular}

B, Bangladesh; CHW, community health worker; G, Guatemala; M, Mexico; NGO, non-governmental organisation; SA, South Africa. 
Table 2 Training methods and duration for CVD and its risk factors management for community health workers in low-income and middle-income countries

\begin{tabular}{|c|c|c|c|}
\hline Study & Training details & $\begin{array}{l}\text { Duration of training } \\
\text { programme }\end{array}$ & $\begin{array}{l}\text { Methods of training (workshop, } \\
\text { online) }\end{array}$ \\
\hline Abrahams-Gessel et al ${ }^{51}$ & $\begin{array}{l}\text { Non-invasive screening of } \\
\text { cardiovascular risk score }\end{array}$ & $\begin{array}{l}\text { Hours of training not reported ( } 2 \\
\text { weeks training over } 4 \text { months) }\end{array}$ & $\begin{array}{l}\text { Lectures and interactive lessons } \\
\text { On-site training for anthropometrical } \\
\text { measurements } \\
\text { BMI and CVD risk score calculation }\end{array}$ \\
\hline Da Silva et $a l^{48}$ & $\begin{array}{l}\text { Hypertension knowledge } \\
\text { and basic skills practices } \\
\text { development }\end{array}$ & $\begin{array}{l}16.5 \text { hours ( } 11 \text { sessions } \\
\text { fortnightly over } 6 \text { months) }\end{array}$ & Lectures and practical sessions \\
\hline Fatmah $^{49}$ & $\begin{array}{l}\text { Obesity and hypertension } \\
\text { knowledge } \\
\text { BMI metric tool } \\
\text { measurements }\end{array}$ & 11 hours (2 days) & $\begin{array}{l}\text { Lectures and interactive sessions } \\
\text { On-site training for BMI metric tool } \\
\text { measurements }\end{array}$ \\
\hline Ku and Kegels ${ }^{53}$ & $\begin{array}{l}\text { Diabetes knowledge and } \\
\text { basic skills practices } \\
\text { development }\end{array}$ & 32 hours & $\begin{array}{l}\text { Lectures, two-way } \\
\text { demonstrations and hands-on } \\
\text { workshops }\end{array}$ \\
\hline Sangprasert ${ }^{47}$ & $\begin{array}{l}\text { Hypertension knowledge } \\
\text { and basic skills practices } \\
\text { development }\end{array}$ & Not reported & Lectures and group discussions \\
\hline Seyed Emami et $a l^{50}$ & $\begin{array}{l}\text { Health education about } \\
\text { physical activity }\end{array}$ & 2.5 hours (three weekly sessions) & Lectures andgroup discussions \\
\hline $\begin{array}{l}\text { Sranacharoenpong and } \\
\text { Hanning }^{52}\end{array}$ & $\begin{array}{l}\text { Hypertension knowledge } \\
\text { and basic skills practices } \\
\text { development }\end{array}$ & $\begin{array}{l}40 \text { hours ( } 16 \text { sessions, over } \\
4 \text { months) }\end{array}$ & $\begin{array}{l}\text { Lectures, group discussion, problem- } \\
\text { based learning, e-learning and online } \\
\text { support } \\
\text { Community-based application } \\
\text { Assignments and self-evaluations }\end{array}$ \\
\hline
\end{tabular}

BMI, body mass index; CVD, cardiovascular disease.

burden through interactive classes. ${ }^{48}$ The training varied, from 2.5 hours $^{50}$ up to 40 hours ${ }^{52}$ over a $4-6$ month period (table 2). Training took place at the local health units in four studies, ${ }^{485} 5254$ while the other three studies did not mention details about the training site. Training focused on CVD and its risk factors, healthy lifestyle and dietary habits and physical activity. Four of the studies ${ }^{47} 51-53$ trained CHWs on anthropometrical measurement skills and their interpretation, and one study trained CHWs to use a body mass index metric tool for nutritional status assessment of the elderly. ${ }^{49}$ None of the studies made their training materials publicly available. Please see table 3 for details about training content of each study.

\section{Impact of the training on knowledge and skills}

All the studies assessed the knowledge ${ }^{47-54}$ and five of them assessed knowledge and skills ${ }^{479}{ }^{51-53}$ before and after the training sessions. In addition, two studies evaluated the effect of training at $3-6$ months $^{51}$ and 8 months after the intervention study. ${ }^{52}$ Pretraining and post-training mean scores were reported by all studies as a measure of effectiveness of training. Of the eight studies included in the review, we could use scores from seven studies; the eighth study ${ }^{47}$ could not be included in the figure as the measure of test scores was not described. All the studies showed increase in the knowledge mean scores among CHWs pretraining and post-training ranging from $3 \%^{48}$ to $40 \%,{ }^{51}$ with six of the studies reporting statistically significant difference between the base knowledge level and post-training knowledge level of the CHWs. ${ }^{47} 49052-54$ In the two studies (including five sites) that assessed the knowledge postintervention, the knowledge level of CHWs in Bangladesh did not change, the CHWs in Guatemala $^{51}$ showed an average increase of $11 \%$ and the scores of CHWs in Mexico, South Africa ${ }^{51}$ and Thailand ${ }^{52}$ decreased over time. Figure 2 provides details regarding the change of the test scores and reported statistical significance of the pretraining-post-training knowledge scores.

One study assessed the counselling skills of the participant CHWs at baseline, 1 month and 2 months posttraining through field visits. ${ }^{49}$ In addition, two projects used qualitative methods to assess the potential challenges and enablers of CHW training programmes, through observation, interviews and focus group discussions. ${ }^{515657}$

CHWs preferred a minimum 2-week training programmes with interactive classes. Since this was the first time many CHWs were offered training in such a setting, it wasn't clear to them what to expect from the training session or workshops. Language barrier was 
Table 3 Training content for CVD and its risk factors management for community health workers in low-income and middleincome countries

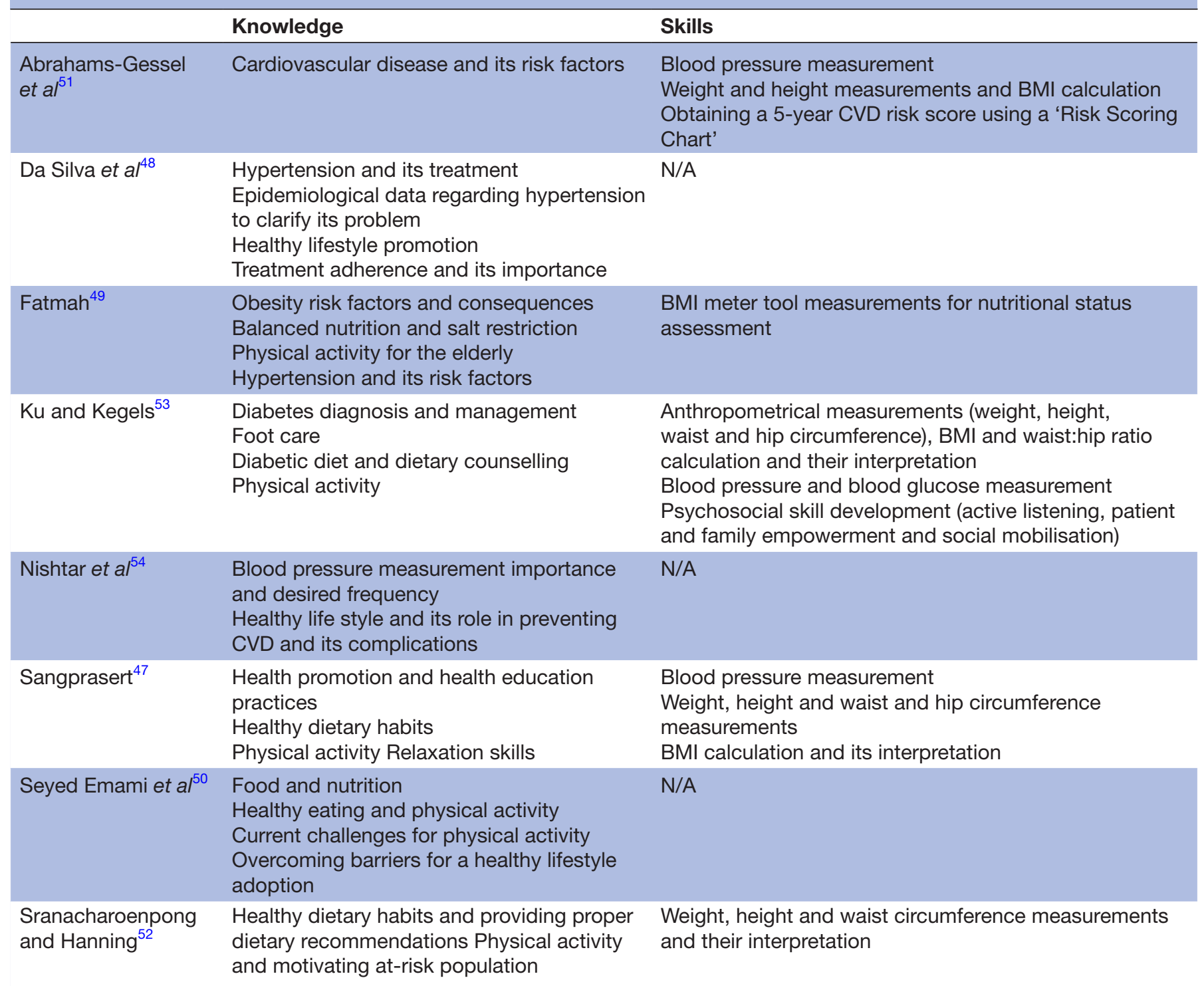

BMI, body mass index; CVD, cardiovascular disease.

another challenge; as the training manual was written in the local language, while the medium of instruction was in English, this made it difficult for the CHWs to link the manual with the verbal instructions provided. Barriers experienced while working in the field included gender issues such as taking anthropometrical measurements of the opposite sex, lack of trust among community to share their health concerns with CHWs, safety and other cultural issues. ${ }^{5158} 59$ In addition, heavy workload, underestimation of the time required to carry out the work and low remuneration provided were other barriers raised by CHWs. In terms of frequency of access to learning materials and satisfaction with the training programme (including length, methods and usefulness of the programme, computer skills and using electronic and paper-based materials), CHWs seemed satisfied with the content of training programme and the assignments.
However, about $46 \%$ did not feel that computer skills were easy to learn.

\section{Study quality}

One out of the eight studies was a randomised controlled trial, ${ }^{52}$ while the others were preobservational and postobservational studies. The CHW retention rates varied across the studies from $77 \%^{51}$ to $88 \%^{53}$ with two studies retaining $100 \%$ of $\mathrm{CHWs}^{485}$ and one study not reporting CHW turnover during the study period. ${ }^{47}$ Detailed information about CHWs,${ }^{54}$ trainers, ${ }^{47}{ }^{52}$ development of the training programme ${ }^{4854}$ and process of knowledge evaluation ${ }^{54}$ was not reported in some studies. The quality of all included studies was assessed using EPHPP's Quality Assessment Tool. ${ }^{46}$ Evaluated across six quality domains, each study was assessed with the potential of an overall rating of weak, moderate or strong. The quality of two 


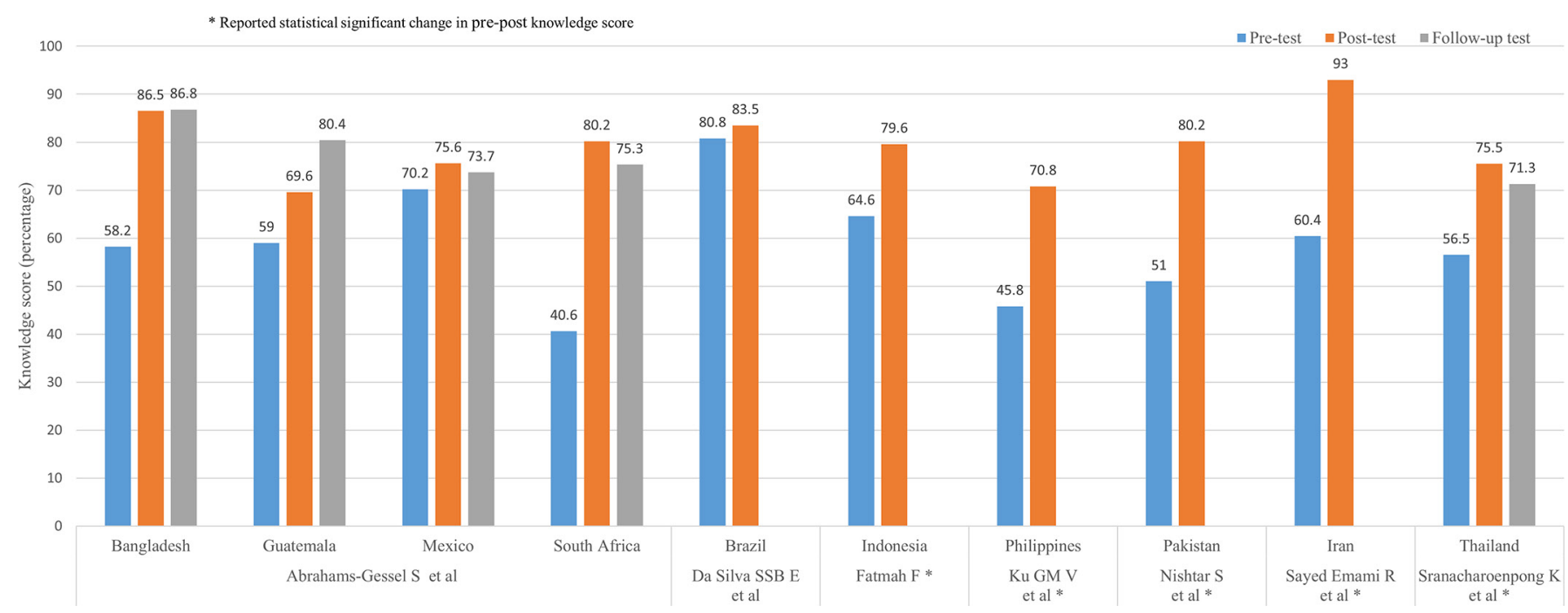

Figure 2 Change in knowledge scores among community health workers.

studies was rated moderate. ${ }^{50} 52$ The others were rated weak. Please see table 4 for details of the quality assessment for each of the six quality domains.

\section{DISCUSSION}

In this review, we assessed the effectiveness of training CHWs for the prevention and management of CVD and its risk factors. We reviewed eight studies, which focused on CVD, hypertension, diabetes or physical activity. The limited evidence available from this review demonstrates that CHWs with low levels of formal education can be trained effectively for CVD and risk factor prevention and management. The results of this review need to be assessed in light of the study quality, which was rated as weak to moderate using the EPHPP's tool. The knowledge and skill set of CHWs improved in the immediate posttraining period for all studies and varied in performance in the $6-8$ months after the initiation of the intervention. The limited qualitative data from two studies ${ }^{5156} 57$ indicate that interactive training, hands-on workshops and case scenarios were preferred over traditional didactic training. Training sessions adapted to local culture and delivered in the local language were found to be easier for the CHWs to understand and retain. Since measurement of cardiovascular risk factors involves taking blood pressure, height, weight and waist measurements in both men and women, understanding the cultural norms was an essential component to deliver the training to CHWs who were women in most studies.

Regardless of the baseline knowledge scores of the trained CHWs, most of the post-training knowledge scores ranged between $70 \%$ and $80 \%$. The two studies ${ }^{5152}$ that measured knowledge at 6-8 months post-training showed that the majority of CHWs had a small decline in their scores, demonstrating their retention of knowledge to certain degree over a period of $6-8$ months. Further research is needed to assess the ideal interval for retraining to ensure long-term improvement in knowledge and consequent improvement in health outcomes for the community. A review of CHW training for maternal and child health-related conditions ${ }^{60}$ and mental health ${ }^{61}$ found that, without retraining, acquired skills and knowledge are lost over time. Different time intervals of refresher training were found to be effective to retain the capability and performance of CHWs. Various studies conducted in different countries had diverse experiences using monthly, quarterly and yearly refresher trainings to help CHWs maintain consistent performance. ${ }^{60}$ While training is an important determinant of performance, other factors related to training include recognition of competence in skills to perform related tasks. Hence, contemporary CHW training programmes now include competency-based training rather than the traditional knowledge-based training. Recent reviews on task shifting from physicians to non-physicians for management of CVD and other NCDs in LMICs have found that training, close supervision and feedback are essential for the success of task-shifting interventions. ${ }^{25} 62$ Training of CHWs occurs through formal schooling, in-service training and on-the-job experience, and these, coupled with the working environment, supervision, motivation, career progression and incentives, determine the long-term effectiveness and performance of CHWs ${ }^{63}$ which ultimately impacts the health of individuals in the community.

While the focus of this paper was knowledge change, results from some of these studies have demonstrated the effectiveness of CHW training on health outcomes. For instance, trained CHWs in Bangladesh, Guatemala, Mexico and South Africa could correctly identify individuals at high risk of CVD, ${ }^{51}$ and CHW screening had high concordance with health professionals. In Indonesia, the posbindu health workers were successful in motivating the elderly to actively engage with the healthcare providers and have better access to healthcare. ${ }^{49}$ In the Philippines, barangay health workers trained in diabetes care 


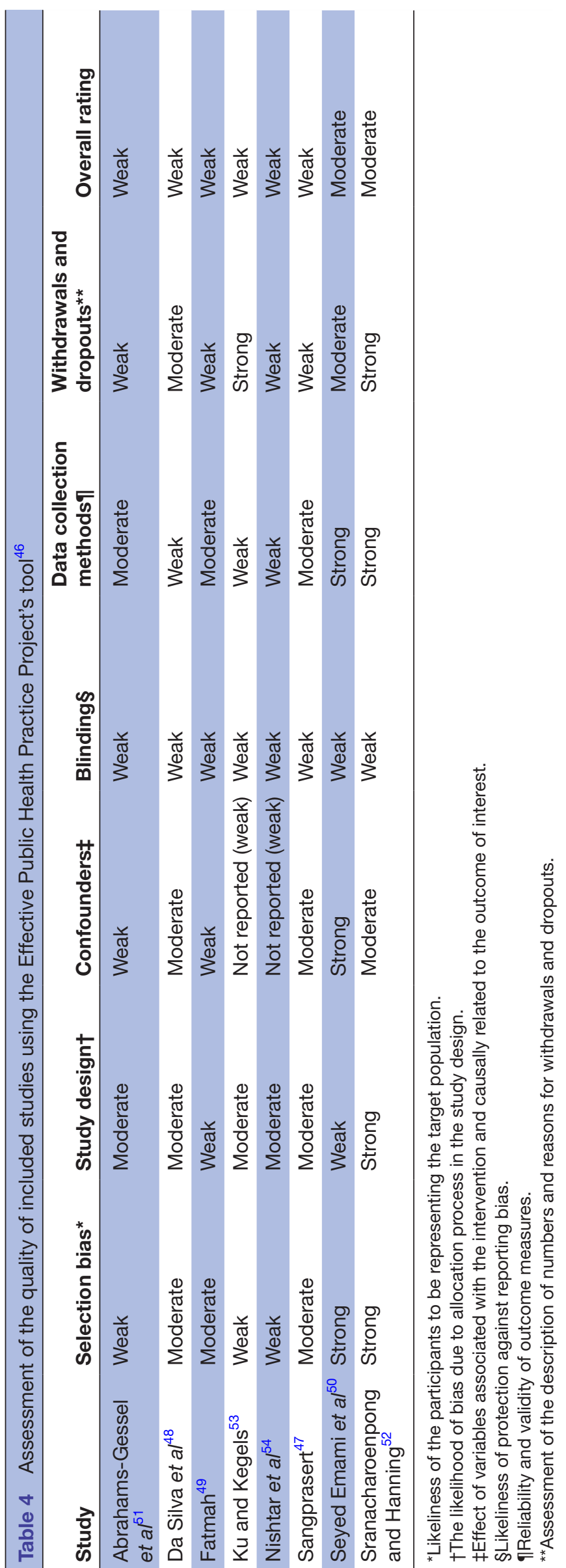

were instrumental in improving glycaemic control among diabetics. ${ }^{53}$ In Pakistan, trained CHWs were successful in educating communities in cardiovascular risk factors. ${ }^{54}$

Over the last 10 years, there have been several studies involving CHWs for the prevention and management of CVD risk factors via complex multifaceted interventions in LMICs. ${ }^{64} 65$ While most studies that involve CHWs include a component of training, none of them report the content, length or effectiveness of training on CHWs. Studies from South Africa, ${ }^{66} 67$ Pakistan, ${ }^{68}$ India, ${ }^{69-71}$ China,${ }^{72}$ Dominican Republic, ${ }^{73}$ Guatemala,${ }^{74}$ Thailand, ${ }^{75}$ Mexico $^{76}$ and the Mexican-USA border ${ }^{77}$ have shown innovative ways of involving CHWs for the prevention and control of CVD and its risk factors. However, these studies did not measure the impact of training on CHW knowledge and skill set.

Testing knowledge and skills via pretraining and posttraining tests does not necessarily reflect the trainee's competence and successful demonstration of behaviour change or change in capability. Standardised measures need to be considered for quality and efficacy assessment of CHW training programmes. Few standardised tools and methods for training evaluation and effectiveness assessment are available ${ }^{78-81}$ which focus on the shortterm and long-term outcomes of the training. Kirkpatrick's Four-Level Training Evaluation Model ${ }^{81}$ is one such method, which is based on evaluating the trainees' reaction to the training programme, improvement in knowledge, the degree to which they apply the knowledge and the long-term outcomes. Kaufman's 5 Levels of Evaluation $^{80}$ is another standard for evaluating the effectiveness of training, which evaluates the training design, materials and resources used and the final outcome on the whole community and the trainee. Using standardised methods of evaluation allows better comparison and interpretation of the data.

This review was not able to explain the difference in the knowledge gained by CHWs within and across knowledge and the variability of the training duration and contextual factors. For instance, the knowledge scores of the CHWs in South Africa, Guatemala and Bangladesh were higher than the scores of CHWs in Mexico, even though all four sites were part of the same trial with the same training protocol. ${ }^{51}$ Hence, research is needed to understand the training needs of the CHWs and community requirements for the successful roll out of CHW-focused interventions on CVD prevention and control. Randomised controlled trials involving CHWs should provide details about the CHW characteristics, curriculum development, training provided and impact of the training, and these should ideally be costed. Mixed-methods studies would give a better understanding of the challenges involved with implementing training programmes for CHWs and provide evidence for best practice. Training design should consider the background education and prior training received, current roles of the CHWs and how the new skills should complement this role. Training should include demonstration, simulation and on-the-job supervision 
to improve confidence of CHWs with their newly learnt skills. Communication skills training should focus on changing social norms and behaviours and encouraging the community to work on local fears and myths. CHW attitudes, expression of respect, responsibility and concern should be addressed in training design to assure development of appropriate relationship between the CHWs and the patients and rest of the community. ${ }^{82}$ With the available mobile conferencing platforms, follow-up training can be provided to many trainees at a time, remotely as well. Training should be provided onsite where CHWs perform their roles, evidence suggest that onsite training tends to cost less and cause less disruption of the routine functioning of health services, compared with offsite training. ${ }^{83}$ Better training programmes alone will not solve the problems related to opportunities for career growth and professional development via continuing education; the chance to move to the next level within the health system would help motive CHWs to stay in the workforce ${ }^{60}$ Attention needs to be paid to CHW remuneration and career development as these are noted challenges affecting the retention of trained CHWs in the workforce. Governments should adopt innovative national planning and provide suitable financial and legal support to ensure the sustainability of implemented programmes. ${ }^{84-87}$ Researchers should consider making the tool kits and resources for CVD management publicly available to other researchers and governments.

Even though our search included all the CHW terminologies used by WHO and recent reviews on CHWs, ${ }^{44}$ we may have missed some studies. After expanding the search to include all languages and extending the time limit to the end of 2016, our search identified only eight studies. The insufficient reporting of study details such as CHWs' characteristics, training site and trainers' profiles led to limited understanding of the contextual factors that influenced the training. Most of the studies were not controlled trials, which made it difficult to investigate the effect of potential confounders. This review included CHWs who were part of the health system and those that volunteered their services. We acknowledge that there is a difference between health volunteers and CHWs, ${ }^{88}$ but since the overall aim of the paper was to evaluate the effectiveness of training programmes, remuneration would have little impact on the change in knowledge and skill set. Despite these limitations, our review indicates that training CHWs about CVD and its risk factors is plausible in LMICs.

In conclusion, this review demonstrates that there is not much information about CHW training for CVD prevention and control in LMICs. While the results of the eight included studies suggest that CHWs can be trained effectively for CVD prevention and management, this finding would likely vary depending on context, given the numerous differences between studies (eg, populations, settings and programmes) and the weak quality of six of the eight studies. Well-conducted mixedmethods studies are needed to provide reliable evidence about the effectiveness and cost-effectiveness of training programmes for CVD prevention and management.

Contributors BP drafted the protocol under the supervision of RJ. BP and MAA performed the search, extracted the data and contributed towards the interpretation of the results. MAA wrote the first draft. RJ conceived the research question, supervised the review and approved the final version of the manuscript. DP and SA provided critical input towards the manuscript. All the authors reviewed the final draft.

Funding This study was not funded by any agency

Competing interests None declared.

Patient consent Detail has been removed from this case description/these case descriptions to ensure anonymity. The editors and reviewers have seen the detailed information available and are satisfied that the information backs up the case the authors are making.

Provenance and peer review Not commissioned; externally peer reviewed.

Data sharing statement All the data are included in the systematic review and the supplementary files. There are no extra data available.

Open Access This is an Open Access article distributed in accordance with the Creative Commons Attribution Non Commercial (CC BY-NC 4.0) license, which permits others to distribute, remix, adapt, build upon this work non-commercially, and license their derivative works on different terms, provided the original work is properly cited and the use is non-commercial. See: http://creativecommons.org/ licenses/by-nc/4.0/

(c) Article author(s) (or their employer(s) unless otherwise stated in the text of the article) 2017. All rights reserved. No commercial use is permitted unless otherwise expressly granted.

\section{REFERENCES}

1. Mathers CD, Loncar D. Projections of global mortality and burden of disease from 2002 to 2030. PLoS Med 2006;3:e442.

2. Omran AR. The epidemiologic transition: a theory of the epidemiology of population change. 1971. Milbank $Q$ 2005;83:731-57.

3. World Health Organization. Fact sheet. World Health Organization. Fact sheet. Secondary Cardiovascular diseases (CVDs). 2016 http:// www.who.int/mediacentre/factsheets/fs317/en/.

4. Celermajer DS, Chow CK, Marijon E, et al. Cardiovascular disease in the developing world: prevalences, patterns, and the potential of early disease detection. J Am Coll Cardiol 2012;60:1207-16.

5. Maher D, Ford N, Unwin N. Priorities for developing countries in the global response to non-communicable diseases. Global Health 2012;8:14.

6. Reddy KS, Yusuf S. Emerging epidemic of cardiovascular disease in developing countries. Circulation 1998;97:596-601.

7. Crouse HL, Macias CG, Cruz AT, et al. Utilization of a mobile medical van for delivering pediatric care in the bateys of the Dominican Republic. Int J Emerg Med 2010;3:227-32.

8. Scheffler RM, Liu JX, Kinfu Y, et al. Forecasting the global shortage of physicians: an economic- and needs-based approach. Bull World Health Organ 2008;86:516-23.

9. World Health Organization. The World Health Report 2006: Working together for health, 2006.

10. Sharma DC. India still struggles with rural doctor shortages. Lancet 2015;386:2381-2.

11. Chen L, Evans T, Anand S, et al. Human resources for health: overcoming the crisis. Lancet 2004;364:1984-90.

12. Lehmann U, Sanders D. Community health workers: what do we know about them. The state of the evidence on programmes, activities, costs and impact on health outcomes of using community health workers. Geneva: World Health Organization, 2007:1-42.

13. Vaughan K, Kok MC, Witter S, et al. Costs and cost-effectiveness of community health workers: evidence from a literature review. Hum Resour Health 2015;13:71.

14. Neupane D, Kallestrup P, McLachlan CS, et al. Community health workers for non-communicable diseases. Lancet Glob Health 2014;2:e567.

15. Gilmore B, McAuliffe E. Effectiveness of community health workers delivering preventive interventions for maternal and child health in low- and middle-income countries: a systematic review. BMC Public Health 2013;13:1. 
16. Tran N, Portela A, de Bernis L, et al. Developing capacities of community health workers in sexual and reproductive maternal, newborn. PLOS 2014.

17. Lawn J, Kerber K. Opportunities for Africas newborns: practical data policy and programmatic support for newborn care in Africa. Switzerland: WHO on behalf of The Partnership for Maternal Newborn and Child Health, 2006.

18. Lewin S, Munabi-Babigumira S, Glenton C, et al. Lay health workers in primary and community health care for maternal and child health and the management of infectious diseases. Cochrane Database Syst Rev 2010;3:CD004015.

19. Lassi ZS, Bhutta ZA. Community-based intervention packages for reducing maternal and neonatal morbidity and mortality and improving neonatal outcomes. Cochrane Database Syst Rev 2015;3:CD007754.

20. Mwai GW, Mburu G, Torpey K, et al. Role and outcomes of community health workers in HIV care in sub-Saharan Africa: a systematic review. J Int AIDS Soc 2013;16:18586.

21. Huicho L, Scherpbier RW, Nkowane AM, et al. How much does quality of child care vary between health workers with differing durations of training? An observational multicountry study. The Lancet 2008;372:910-6.

22. Hermann K, Van Damme W, Pariyo GW, et al. Community health workers for ART in sub-Saharan Africa: learning from experience-capitalizing on new opportunities. Hum Resour Health 2009;7:1.

23. Schneider $\mathrm{H}$, Hlophe $\mathrm{H}$, van Rensburg D. Community health workers and the response to HIV/AIDS in South Africa: tensions and prospects. Health Policy Plan 2008;23:179-87.

24. Simon S, Chu K, Frieden M, et al. An integrated approach of community health worker support for HIV/AIDS and TB care in Angónia district, Mozambique. BMC Int Health Hum Rights 2009;9:1.

25. Joshi R, Alim M, Kengne AP, et al. Task shifting for noncommunicable disease management in low and middle income countries--a systematic review. PLoS One 2014;9:e103754.

26. Lehmann U, Van Damme W, Barten F, et al. Task shifting: the answer to the human resources crisis in Africa? Hum Resour Health 2009; $7: 49$.

27. Joshi R, Santo K, Redfern K. Task shifting for cardiovascular disease management: what can we learn from other models? J Cardiol 2014;1:65-73.

28. Abegunde DO, Shengelia B, Luyten A, et al. Can non-physician health-care workers assess and manage cardiovascular risk in primary care? Bull World Health Organ 2007;85:432-40.

29. Raphael JL, Rueda A, Lion KC, et al. The role of lay health workers in pediatric chronic disease: a systematic review. Acad Pediatr 2013;13:408-20.

30. Balcázar HG, de Heer HD. Community health workers as partners in the management of non-communicable diseases. Lancet Glob Health 2015;3:e508-e509.

31. Mohan V, Deepa M, Pradeepa R, et al. Prevention of diabetes in rural India with a telemedicine intervention. J Diabetes Sci Technol 2012;6:1355-64.

32. Cappuccio FP, Kerry SM, Micah FB, et al. A community programme to reduce salt intake and blood pressure in Ghana [ISRCTN88789643]. BMC Public Health 2006;6:13.

33. Jafar TH, Islam M, Hatcher J, et al. Community based lifestyle intervention for blood pressure reduction in children and young adults in developing country: cluster randomised controlled trial. BMJ 2010;340:c2641.

34. Coleman R, Gill G, Wilkinson D. Noncommunicable disease management in resource-poor settings: a primary care model from rural South Africa. Bull World Health Organ 1998;76:633-40.

35. Farzadfar F, Murray CJ, Gakidou E, et al. Effectiveness of diabetes and hypertension management by rural primary health-care workers (Behvarz workers) in Iran: a nationally representative observational study. Lancet 2012;379:47-54.

36. Alem A, Jacobsson L, Hanlon C. Community-based mental health care in Africa: mental health workers' views. World Psychiatry 2008;7:54-7.

37. Redick C, Dini H.The current state of $\mathrm{CHW}$ training programs in SubSaharan Africa and South Asia: What we know what we dont know and what we need to do. 2014.

38. Waldman R.Health programming for rebuilding states: a briefing paper. 2007.

39. Ryabov I. Cost-effectiveness of Community Health Workers in controlling diabetes epidemic on the U.S.-Mexico border. Public Health 2014;128:636-42.

40. Pallas SW, Minhas D, Pérez-Escamilla R, et al. Community health workers in low- and middle-income countries: what do we know about scaling up and sustainability? Am J Public Health 2013;103:e74-e82.
41. Moher D, Liberati A, Tetzlaff J, et al. Preferred reporting items for systematic reviews and meta-analyses: the PRISMA statement. Ann Intern Med 2009;151:264-9.

42. Lariosa T. The role of community health workers in malaria control in the Philippines. The Southeast Asian journal of tropical medicine and public health 1991;23:30-5.

43. Sharma R, Webster P, Bhattacharyya S. Factors affecting the performance of community health workers in India: a multistakeholder perspective. Glob Health Action 2014;7:25352.

44. Olaniran $\mathrm{A}$, Smith $\mathrm{H}$, Unkels $\mathrm{R}$, et al. Who is a community health worker? A systematic review of definitions. Glob Health Action 2017;10:1272223.

45. The World Bank Country and Lending Groups, 2016.

46. Thomas H. Quality assessment tool for quantitative studies. Effective Public Health Practice Project McMaster University, Toronto 2003.

47. Sangprasert $P$. The effects of a training program for the development of hypertension knowledge and basic skills practice (HKBSP) for Thai community healthcare volunteers. Siriraj Medical Journal 2011;63:163-7.

48. Da Silva S, Colosimo FC, Pierin AMG. The effect of educational interventions on nursing team knowledge about arterial hypertension]. Revista Da Escola de Enfermagem Da Usp 2010;44:488-96.

49. Fatmah F. Training effect on improving cadres' knowledge and skills of obesity and hypertension in older people. Makara $\mathrm{J}$ of Health Research 2014:49-54.

50. Seyed Emami R, Eftekhar Ardebili H, Golestan B. Effect of a health education intervention on physical activity knowledge, attitude and behavior in health volunteers. Journal of hayat 2011;16:48-55

51. Abrahams-Gessel S, Denman CA, Montano CM, et al. The training and fieldwork experiences of community health workers conducting population-based, noninvasive screening for CVD in LMIC. Glob Heart 2015;10:45-54.

52. Sranacharoenpong K, Hanning RM. Diabetes prevention education program for community health care workers in Thailand. $J$ Community Health 2012;37:610-8.

53. Ku GM, Kegels G. Integrating chronic care with primary care activities: enriching healthcare staff knowledge and skills and improving glycemic control of a cohort of people with diabetes through the First Line Diabetes Care Project in the Philippines. Glob Health Action 2014;7.

54. Nishtar S, Badar A, Kamal MU, et al. The Heartfile Lodhran CVD prevention project--end of project evaluation. Promot Educ 2007; $14: 17-27$

55. Salter D, Richards L, Carey T. The 'T5' design model: an instructional model and learning environment to support the integration of online and campus-based courses. EMI Educ Media Int 2004;41:207-18.

56. Sranacharoenpong K, Hanning RM. Developing a diabetes prevention education programme for community health-care workers in Thailand: formative findings. Prim Health Care Res Dev 2011;12:357-69.

57. Sranacharoenpong K, Hanning RM, Sirichakwal PP, et al. Process and outcome evaluation of a diabetes prevention education program for community healthcare workers in Thailand. Educ Health 2009;22:335

58. Gaziano TA, Abrahams-Gessel S, Denman CA, et al. An assessment of community health workers' ability to screen for cardiovascular disease risk with a simple, non-invasive risk assessment instrument in Bangladesh, Guatemala, Mexico, and South Africa: an observational study. Lancet Glob Health 2015;3:e556-e563.

59. Abrahams-Gessel S, Denman CA, Montano CM, et al. Lessons from training and supervision of community health workers conducting non-invasive, population-based screening for cardiovascular disease in four communities in low and middle-income settings: Implications for scaling up. Global heart 2015;10:39.

60. Bhutta ZA, Lassi ZS, Pariyo G, et al. Global experience of community health workers for delivery of health related millennium development goals: a systematic review, country case studies, and recommendations for integration into national health systems. Global Health Workforce Alliance 2010;1:249-61.

61. Armstrong G, Kermode M, Raja S, et al. A mental health training program for community health workers in India: impact on knowledge and attitudes. Int J Ment Health Syst 2011;5:17.

62. Ogedegbe G, Gyamfi J, Plange-Rhule J, et al.Task shifting interventions for cardiovascular risk reduction in low-income and middle-income countries: a systematic review of randomised controlled trials. BMJ open 2014;4:10.

63. Rowe AK, de Savigny D, Lanata CF, et al. How can we achieve and maintain high-quality performance of health workers in low-resource settings? Lancet 2005;366:1026-35. 
64. Kamath DY, Xavier D, Gupta R, et al. Rationale and design of a randomized controlled trial evaluating community health workerbased interventions for the secondary prevention of acute coronary syndromes in India (SPREAD). Am Heart J 2014;168:690-7.

65. van de Vijver S, Oti S, Addo J, et al. Review of community-based interventions for prevention of cardiovascular diseases in low- and middle-income countries. Ethn Health 2012;17:651-76.

66. Surka S, Edirippulige S, Steyn K, et al. Evaluating the use of mobile phone technology to enhance cardiovascular disease screening by community health workers. Int J Med Inform 2014;83:648-54.

67. Botes AS, Majikela-Dlangamandla B, Mash R. The ability of health promoters to deliver group diabetes education in South African primary care. African Journal of Primary Health Care and Family Medicine. 2013;5.

68. Khan M, Kamal AK, Islam M, et al. Can trained field community workers identify stroke using a stroke symptom questionnaire as well as neurologists? Adaptation and validation of a community worker administered stroke symptom questionnaire in a peri-urban Pakistan community. J Stroke Cerebrovasc Dis 2015;24:91-9.

69. Balagopal P, Kamalamma N, Patel TG, et al. A community-based participatory diabetes prevention and management intervention in rural India using community health workers. Diabetes Educ 2012;38:822-34.

70. Xavier D, Gupta R, Kamath D, et al. Community health worker-based intervention for adherence to drugs and lifestyle change after acute coronary syndrome: a multicentre, open, randomised controlled trial. Lancet Diabetes Endocrinol 2016;4:244-53.

71. Joshi R, Chow CK, Raju PK, et al. The Rural Andhra Pradesh Cardiovascular Prevention Study (RAPCAPS): a cluster randomized trial. J Am Coll Cardiol 2012;59:1188-96.

72. Fu D, Fu H, McGowan P, et al. Implementation and quantitative evaluation of chronic disease self-management programme in Shanghai, China: randomized controlled trial. Bull World Health Organ 2003;81:1p.

73. West-Pollak A, Then EP, Podesta C, et al. Impact of a novel community-based lifestyle intervention program on type 2 diabetes and cardiovascular risk in a resource-poor setting in the Dominican Republic. Int Health 2014;6:118-24.

74. Micikas M, Foster J, Weis A, et al. A community health worker intervention for diabetes self-management among the Tz'utujil Maya of Guatemala. Health Promot Pract 2015;16:601-8.

75. Saranrittichai K, Senarak W, Promthet S, et al. Health behavior after a multiprofessional intervention and training for ongoing volunteerbased community health programme intervention in the North-East of Thailand: what changed and what not? Asian Pac J Cancer Prev 2012:13:4801-5.
76. Denman CA, Rosales C, Cornejo E, et al. Evaluation of the community-based chronic disease prevention program Meta Salud in Northern Mexico, 2011-2012. Prev Chronic Dis 2014;11:E154.

77. Cornejo E, Denman CA, Sabo S, et al. Scoping review of community health worker/promotora-based chronic disease primary prevention programs on the US-Mexico border. alamo colson edu $\mathrm{mx2011;8085.}$

78. Alvarez K, Salas E, Garofano CM. An integrated model of training evaluation and effectiveness. Human Resource Development Review 2004;3:385-416.

79. Wang GG, Wilcox $D$. Training evaluation: knowing more than is practiced. Adv Dev Hum Resour 2006;8:528-39.

80. Kaufman R, Keller JM. Levels of evaluation: beyond Kirkpatrick. Human Resource Development Quarterly 1994:5:371-80.

81. Bates R. A critical analysis of evaluation practice: the Kirkpatrick model and the principle of beneficence. Eval Program Plann 2004:27:341-7.

82. Perry $\mathrm{H}$, Crigler L. Developing and strengthening community health worker programs at scale. A reference guide and case studies for program managers and policymakers 2013.

83. Puchalski Ritchie LM, Schull MJ, Martiniuk AL, et al. A knowledge translation intervention to improve tuberculosis care and outcomes in Malawi: a pragmatic cluster randomized controlled trial. Implement Sci 2015;10:1.

84. Kok MC, Dieleman M, Taegtmeyer M, et al. Which intervention design factors influence performance of community health workers in lowand middle-income countries? A systematic review. Health Policy Plan 2015;30:1207-27.

85. Abbey M, Bartholomew LK, Nonvignon J, et al. Factors related to retention of community health workers in a trial on community-based management of fever in children under 5 years in the Dangme West District of Ghana. Int Health 2014;6:99-105.

86. Bhattacharyya K, Winch P, LeBan K, et al. Community Health Worker Incentives and Disincentives: How They Affect Motivation, Retention, and Sustainability. Published by the Basic Support for Institutionalizing Child Survival Project (BASICS II) for the United States Agency for International Development. Arlington, Virginia.

87. Maher D, Cometto G. Research on community-based health workers is needed to achieve the sustainable development goals. Bull World Health Organ 2016;94:786-86.

88. Vareilles G, Pommier J, Marchal B, et al. Understanding the performance of community health volunteers involved in the delivery of health programmes in underserved areas: a realist synthesis. Implement Sci 2017;12:22. 